\title{
Structure-Property Correlations in Bending and Brittle Organic Crystals
}

C. Malla Reddy ${ }^{\dagger}$ K. Anantha Padmanabhan ${ }^{*}$, and Gautam R. Desiraju $^{*}$,

$\uparrow$ School of Chemistry, University of Hyderabad, Hyderabad 500 046, India

Fax: (+91) 40-2301-0567; E-mail: gautam_desiraju@yahoo.com

¥ School of Physics, University of Hyderabad, Hyderabad 500 046, India

Fax: (+91) 40-2301-1777; E-mail: ananthaster@gmail.com

Supporting Information

(Pages 3) 
Background of bending and terms used in mechanical metallurgy: The bending process of metal crystals at the atomic level is explained using the theory of dislocations. ${ }^{1}$ The bend radius $R$ is defined as the radius of curvature on the concave or inside, surface of the bend (Figure 1). ${ }^{2}$ The neutral axis is the axis along which there is no change in length as a result of the deformation process. For elastic bending, that is below the elastic limit, the strain passes through zero halfway through the thickness of the sheet at the neutral axis. In plastic bending, that is beyond the elastic limit, with continued bending the neutral axis moves closer to the inside surface of the bend. Since the plastic strain is proportional to the distance from the neutral axis, fibers on the outer surface are stretched and the fibers on the inner surface are compressed. Since the average fiber at the midthickness is stretched, there will be a decrease in thickness (in the radial direction) at the bend to preserve constancy of volume. The smaller the radius of curvature, the greater will be the decrease in thickness on bending. According to the theory of bending ${ }^{3}$ the strain increases with decrease in the radius of curvature. For a given bending operation the bend radius cannot be made smaller than a certain value (minimum bend radius) or the metal will crack on the outer surface subjected to a tensile stress. Some very ductile metals have a minimum bend radius of zero, indicating that they can be flattened upon themselves. ${ }^{2}$

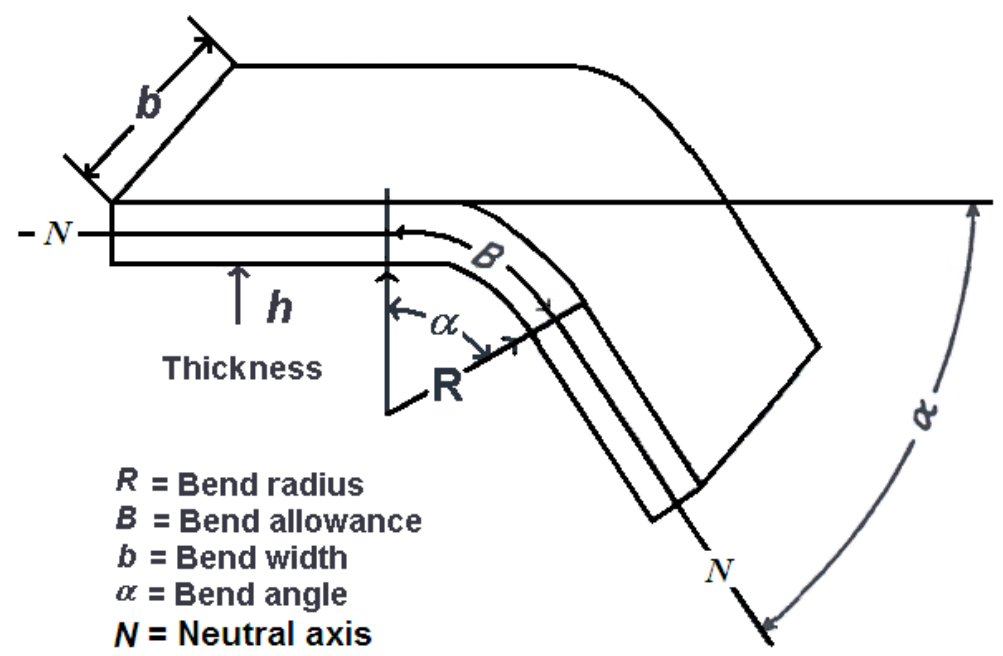

Figure 1. Bending of a metal sheet and definition of terms used in bending ${ }^{2}$ in mechanical metallurgy. 


\section{References}

(1) (a) Cottrell, A. H.; Dislocations and Plastic Flow, Clarendon, Oxford, London, 1953. (b) Kelly, A. Strong Solids, Clarendon Press, Oxford, 1966.

(2) Dieter, G. E. (adapted by Bacon, D.), Mechanical Metallurgy, SI Metric Edition, McGraw-Hill, Singapore, 1988, see p. 659 for a similar depiction for the bending of a metal sheet.

(3) (a) Lubahn, J. D.; Sachs, G. Trans. ASME, 1950, 72, 201. (b) Shaffer, B. W.; Unger, E.E. Trans. ASME, Ser. E: J. Appl. Mech. 1960, 27, 34. 